\title{
Facing the future: Memory as an evolved system for planning future acts
}

\author{
Stanley B. Klein, Theresa E. Robertson, ANd Andrew W. Delton \\ University of California, Santa Barbara, California
}

\begin{abstract}
All organisms capable of long-term memory are necessarily oriented toward the future. We propose that one of the most important adaptive functions of long-term episodic memory is to store information about the past in the service of planning for the personal future. Because a system should have especially efficient performance when engaged in a task that makes maximal use of its evolved machinery, we predicted that future-oriented planning would result in especially good memory relative to other memory tasks. We tested recall performance of a word list, using encoding tasks with different temporal perspectives (e.g., past, future) but a similar context. Consistent with our hypothesis, future-oriented encoding produced superior recall. We discuss these findings in light of their implications for the thesis that memory evolved to enable its possessor to anticipate and respond to future contingencies that cannot be known with certainty.
\end{abstract}

The adaptive function of information storage is intrinsically prospective: It is used to support future decisions and judgments, which cannot be known in advance with certainty. To the extent that the character of subsequent decisions and judgments can be predicted, the memory system can be tailored to flag relevant information and precompute variables that are required to make them.

Klein, Cosmides, Tooby, and Chance (2002, p. 313)

Evidence of complex planning in the human lineage dates back hundreds of thousands of years - for example, organized hunting parties; the creation and transportation of tools; technology; the burying of the dead and provision of supplies for an afterlife; the development of agriculture and with it the village, city, state, and nation (for reviews, see Boyer, 2001; Donald, 1991, 2001; Dunbar, 1996; Gibson \& Ingold, 1993; Johnson, 2003; Mithen, 1996; Mumford, 1934; Passingham, 1982). Much of human mental life and the cultural products that it produces-norms, written and material resources, symbolic representation, abstract thought, science, religion, social complexitiesderives in part from our capacity to orient toward, and plan with respect to, an uncertain but potentially controllable future (e.g., Donald, 1991; Lombardo, 2008).

All organisms capable of long-term memory are necessarily oriented toward the future. A feature of memory apparently unique to humans, however, is the degree to which the decisions and plans that we make are based on representations that are future oriented-imaginings of specific events located forward in time (for reviews, see Bischof-Köhler, 1985; Donald, 1991; Suddendorf, 1994; and Suddendorf \& Corballis, 1997, 2007). The more com- plex, flexible, and temporally extensive the planning process is, the more purposeful and proactive the responses to the environment can be (e.g., Donald, 1991; Lombardo, 2008; Suddendorf, 1994; Suddendorf \& Corballis, 1997). By virtue of this sophistication, our species can both anticipate and plan for future contingencies that transcend our current needs and motivational states (e.g., BischofKöhler, 1985; Suddendorf \& Corballis, 2007). Thus, an evolved capacity to imagine and plan for personal future contingencies, especially plans not tied to current drives and needs, confers an enormous selective advantage on its possessor.

Assuming that memory is a system created by natural selection (and it is; for a discussion, see Klein, 2007, and Klein, Cosmides, et al., 2002), it exists in its present form because that arrangement solved certain recurrent problems faced by the organism in its evolutionary past. Evolution does not produce new phenotypic systems that are complex, metabolically costly, and functionally organized by chance; rather, systems acquire their functional organization because they contributed to the organism's ability to survive and reproduce (e.g., Barkow, Cosmides, \& Tooby, 1992; Dawkins, 1976; Williams, 1966).

An evolved system, defined with respect to functionality, consists of those component processes - and their coordinated interactions - that are necessary to accomplish a specific adaptive task. We suggest that many features of human memory systems have been designed by evolution, in part, to interface with systems for long-term planning. For an organism to behave more appropriately (i.e., more adaptively) at a later time because of experiences at an earlier time, the organism must be equipped not only with mechanisms that retrieve ontogenetically acquired infor-

S. B. Klein, klein@psych.ucsb.edu 
mation, but also with mechanisms that use this information to make decisions and to plan behavior.

\section{The Present Research}

In this article, we propose that one of the most important adaptive functions of human memory is to monitor, store, and access information in the service of planning for personal future contingencies. We argue that when memory is so engaged, its performance should be especially efficient. Our prediction draws on a conceptual distinction proposed by Klein and colleagues between a memory system's capabilities and its functions (e.g., Klein et al., 2009; Klein, Cosmides, et al., 2002).

As is well known, the capabilities of memory systems are vast (for reviews, see Schacter \& Tulving, 1994; and Tulving \& Craik, 2000). These systems can, with varying degrees of success, encode, store, and retrieve an enormous variety of information, including much that is adaptively arbitrary and evolutionarily novel-from nonsense syllables, jingles, and batting averages to chess moves, equations, and the triple lutz. However, there is an important difference between what a system can do and its evolved function. Memory is a system whose parts exist in their present form because of the functional contributions that they made to adaptive behavior in the past (e.g., Klein, Cosmides, et al., 2002). When such a system is engaged by tasks that maximally utilize its evolved machineryfor example, tasks that encourage the memory system to use information acquired in the past to plan and coordinate the organism's behavior in the future-especially efficient performance is likely to be found.

In the present study, we compared memorial performance for a set of encoding tasks that differed with respect to the temporal orientation that they encouraged the participant to take while he or she thought about a list of experimentally presented stimuli. All of the participants were asked to imagine being in the woods. In the past-oriented encoding condition, the participants were instructed to recall a specific time in their past when they went camping in the woods and then to determine whether each item in the list was part of their memory of the recalled experience. In the future-oriented condition, the participants were asked to imagine that they were planning to go camping and then to decide whether each of the items in the list was relevant to planning their trip. In the atemporal condition, the participants were asked to use their generic (i.e., nonpersonal, semantic) knowledge of camping to form an image of a camping trip and then to decide whether each item was part of their representation. In this condition, no mention was made of the temporal placement (i.e., past, present, or future) of the camping context. Following encoding, the participants received a surprise recall test in which they were asked to remember as many list words as possible.

We predicted that the task designed to encourage planning for the future (i.e., the planning task) would produce reliably higher recall of list items than would either the past-oriented or the atemporal task. Planning, like any cognitive process, is metabolically costly. Moreover, in any planning process, one can consider a potentially limit- less number of contingencies, only a subset of which will ultimately be acted on. Because of this, a memory system well adapted for interfacing with planning systems should include a design feature that tracks whether a given course of action (e.g., bringing a raincoat to the woods) has been considered during the current planning routine. This should occur even if the potential course of action is ultimately determined to be irrelevant; indeed, it would be particularly wasteful to reconsider a course of action already deemed useless. Therefore, engaging in planning (e.g., by considering whether a series of objects would be useful for a future camping trip) should elicit recall superior to that found for tasks that fail to encourage future orientation. As a comparison with planning, we used a past-oriented and an atemporal task. Although planning often involves sequentially considering a number of alternatives, these latter two conditions clearly do not.

We further predicted that the past-oriented and atemporal tasks would be roughly equivalent in the amount of recall that they produced (although it would be lower than that found for the future-oriented planning task). We made this prediction on the basis of Klein and colleagues' finding that tasks equated for the amount of organization that they encourage typically yield comparable recall performance (e.g., Klein \& Kihlstrom, 1986; Klein \& Loftus 1988, 1990; for a review, see Symons \& Johnson, 1997). Since the past-oriented and atemporal encoding tasks encourage organization of list items into the same two conceptually meaningful categories - items associated with camping and items not associated with camping - any recall differences between tasks were anticipated to be minimal. ${ }^{1}$

\section{Survival Versus Planning}

Although not directly part of the logic motivating our study, we included a fourth encoding condition, in which the participants were once again asked to imagine that they were in the woods but, this time, were asked to judge which of the items on the stimulus list would be relevant to their survival. The inclusion of this condition was motivated by a recent program of research by Nairne and his colleagues (e.g., Nairne \& Pandeirada, 2008a, 2008b; Nairne, Pandeirada, \& Thompson, 2008; Nairne, Thompson, \& Pandeirada, 2007), who argued that memory systems are "tuned" to remember information that is evolutionarily relevant (see also Kenrick, Delton, Robertson, Becker, \& Neuberg, 2007; Klein, Cosmides, et al., 2002; Maner et al., 2003). Empirically, Nairne and colleagues addressed the effects of processing information for its relevance to survival. Although survival processing per se is unlikely to be a unified domain (and therefore unlikely to be handled by a single cognitive mechanism; see Nairne \& Pandeirada, 2008b), there is a strong a priori likelihood that it will activate at least some specialized motivational machinery that interfaces with memory. Nonetheless, survival processing, as it was operationalized in these studies, tends to partially confound survival with planning: Survival often entails a future orientation and planning (to varying degrees, depending on the goal, task, and situation). Survival, per se, however, is not a 
logically necessary component of the planning process. For example, it is perfectly possible to plan for a birthday party, for a lunch date, or for conducting a psychological study without considering the survival relevance of those plans. Thus, it should be possible to examine the contributions of planning to subsequent recall by adopting a planning task that is future oriented but that has minimal relevance for survival.

Cognizant of the potential confounding of survival and future planning, Nairne and colleagues (Nairne \& Pandeirada, 2008a, 2008b; Nairne et al., 2008; Nairne et al., 2007) did include a "planning" condition in some of their studies. Memory in the survival condition reliably exceeded that for tasks that encouraged planning. However, because the scenarios used across conditions were varied in these experiments (e.g., surviving in the woods vs. planning an extended vacation in a foreign country), it remains difficult to determine whether the superior recall in their survival condition was due to the encoding task, the context of encoding, or some combination of the two.

In our study, the context of encoding was held constant across conditions. List words were evaluated with respect to the same scenario: being in the woods. We predicted that although recall in the survival task condition should exceed that found for either the past-oriented or atemporal task (e.g., Nairne et al., 2007), it would be inferior to that found for the planning task. This is because the planning task explicitly requires the participants to evaluate a stimulus material with respect to future-oriented goals, whereas the participants who perform the survival task, which does not explicitly mention planning, have considerable flexibility in the degree to which planning plays a part in their survival processing. For example, some participants may conceptualize survival in terms of their immediate needs, whereas others think of it in terms of planning for future or long-term survival goals. The potential variability in the degree of planning associated with survival should lessen the overall memorial effectiveness of the task when compared with a task (the future-oriented planning task) that makes planning central to its successful performance.

\section{Pretesting}

Prior to undertaking the main experiment, we felt it important to show that planning a camping trip does not typically evoke survival concerns in our undergraduate population (if it did, survival, rather than planning, per se, might be responsible for the high level of recall predicted for planning processing). To evaluate this possibility, we conducted a series of pretests. In our first pretest, 15 undergraduates were asked to complete a questionnaire containing 18 words representing both material objects (e.g., food, plants, pencils) and more abstract concepts (e.g., fun, surprise, survival). The complete list can be seen in either Figure 1 or Figure 2. The instructions requested that the participants

take a few moments to imagine that you are going on a camping trip. Pay attention to all of the feelings and thoughts that go through your mind as you imagine going on this trip. To what extent does each of the following words describe what was going through your mind as you thought about your trip?

The participants then received a sheet of paper with the 18 words (each participant viewed one of two random orderings of the list) and were asked to rate each word for the extent to which it captured their thoughts or feelings as they imagined their trip. Scale values ranged from 1 (not at all) to 5 (very much).

The results, presented in Figure 1, show, as was expected, that camping-relevant items such as fun, food, trees, and recreation received the highest scores $(M \mathrm{~s} \geq 3)$, whereas

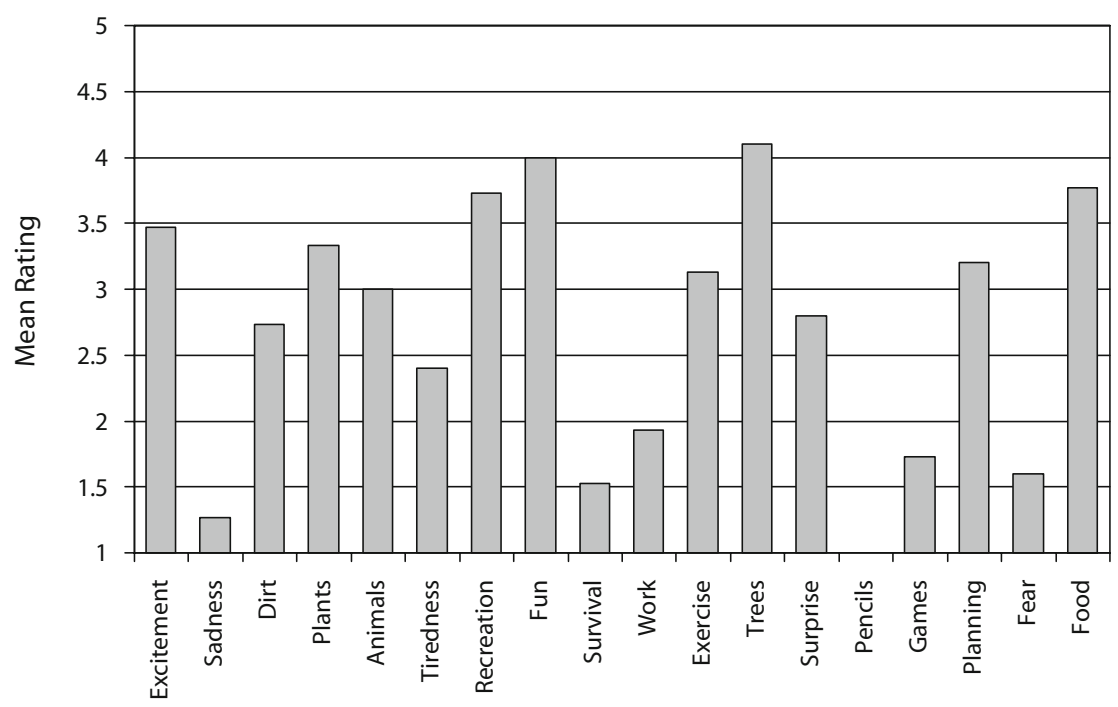

Figure 1. Mean ratings of 18 stimulus words with respect to their relevance to going on a camping trip. Scale values ranged from 1 (not at all) to 5 (very much). 
items with low a priori relevance to camping (e.g., pencil, sadness, fear, work) clustered near the bottom of the scale ( $1 \leq M \leq 2)$. Of most relevance, survival received a rating of 1.53 , placing it only half a point above the scale value designated not at all.

It might be argued that although survival is not high on the participants' list of things that they associate with being on a camping trip, survival-related thought and emotion play a larger role in planning for a trip. Since planning is the focal element of the present study, we decided to repeat our pretest with a new set of participants $(N=18)$ and a slight change in the instructions. The participants were treated in the same manner as were those in the first pretest, with the one alteration: The word going was changed to the word planning. The resulting instructions read,

Take a few moments to imagine that you are planning a camping trip. Pay attention to all of the feelings and thoughts that go through your mind as you imagine planning this trip. To what extent does each of the following words describe what was going through your mind as you made your plans for the trip?

As can be seen in Figure 2, the results were essentially identical to those found in the previous pretest. Pencils, sadness, and fear were seldom thought about, whereas excitement, recreation, trees, and fun were often on the participants' minds. Of critical interest, survival once again fell near the bottom of the scale $(M=1.72)$, a score that exceeded only those for sadness, surprise, fear, and pencils. Not surprisingly (and serving as a quasi-manipulation check), the item planning was rated high $(M=3.83)$.

In summary, although it is always possible to argue that survival concerns play a nonconscious role in cognition about camping (whether in the past, present, or future), the participants' subjective reports revealed little, if any, conscious concern with survival in the camping setting. On the basis of these findings, and the arguments presented above, we predicted that the recall performance associated with a task encouraging planning should exceed one encouraging survival, which, in turn, should exceed both atemporal and past-oriented processing. The two latter task types were not predicted to differ reliably.

\section{METHOD}

\section{Participants}

The participants were 224 undergraduates in an introductory psychology class. The experiment was conducted in a single masstesting session, lasting approximately $20 \mathrm{~min}$.

\section{Materials}

The participants were randomly assigned to one of four encoding conditions ( $n=56$ per condition).

In the past condition, the participants received the following instructions:

Remember a specific time in your past that you went camping in the forest. What items do you remember taking with you on your camping trip? Below, you will find a list of words describing physical objects. I would like you to rate how likely it was that each of the objects on the list was at the camping trip you remember. For some objects, it may be likely that you brought them on your trip. For others, it may be unlikely. It is up to you to decide.

In the atemporal condition, the participants were told,

Use your imagination to form a picture of a campsite in a forest. What items appear in the image that you have created of the campsite? Below, you will find a list of words describing physical objects. I would like you to rate how likely it is that each of the objects on the list is at the campsite that you have imagined. For some objects, it may be likely that they appear in your image. For others, it may be unlikely. It is up to you to decide.

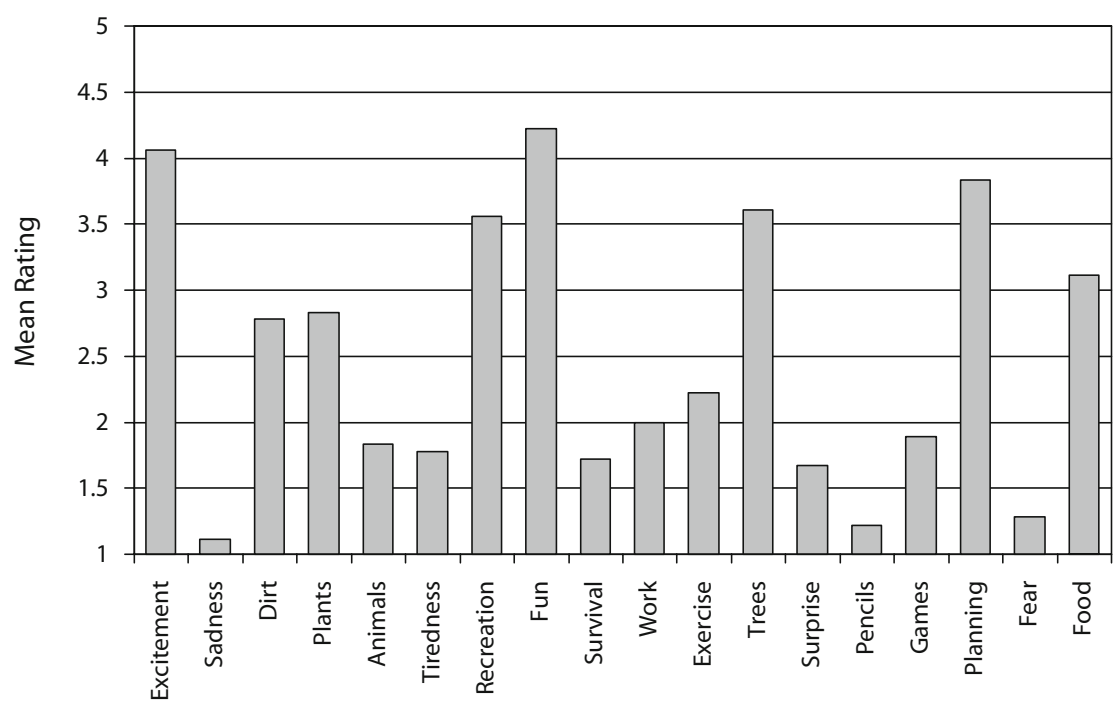

Figure 2. Mean ratings of 18 stimulus words with respect to their relevance to planning a camping trip. Scale values ranged from 1 (not at all) to 5 (very much). 
In the planning condition, the participants were instructed to

imagine that you are making plans to take a camping trip in the forest. What items would you plan to take with you? Below, you will find a list of words describing physical objects. I would like you to rate how likely it is that you would take each of the objects on the list as you plan your camping trip. For some objects, it may be very likely that you take them. For others, it may be unlikely. It is up to you to decide.

Finally, the participants in the survival condition received instructions that mirrored those used by Nairne et al. (2007), with changes made where necessary to ensure comparability to the instructions in the other encoding conditions. The participants were told to

imagine that you are stranded in a forest without any basic survival material. What items would you need to help you to survive in this situation? Below, you will find a list of words describing physical objects. I would like you to rate how likely each of these objects would be to increase your chances for survival. Some objects may be very likely to be of help. Others may be unlikely. It is up to you to decide.

All of the participants viewed the same list of 30 stimulus words. The words all represented moveable physical objects (e.g., television, rug, rope, knife; the complete list can be found in the Appendix). Pretesting $(N=27)$ indicated that 15 of the words were objects likely to be associated with spending time in the woods (items that scored $M \mathrm{~s} \geq 3.8$ on a 5 -point scale-1, very unlikely; 5 , very likely) and 15 represented objects unlikely to be associated with spending time in the woods $(M \leq 2.2)$. Half of the participants in each experimental condition were randomly assigned to receive one of two random orderings of the list words.

\section{Design and Procedure}

At the start of the experiment, each participant received a 5-page booklet containing the experimental material appropriate to his or her condition. The first page contained instructions describing the encoding task that they would perform (see above). Underneath the task instructions were the 30 list words, printed 1 per line. Each word was accompanied by a 5-point scale that ranged from 1 (very unlikely) to 5 (very likely). Three minutes were allotted to complete this portion of the experiment (pretesting indicated that this interval was sufficient for the participants to read the instructions and to make their ratings at a comfortable pace).

Following the rating/encoding task, the participants turned to page 2, where the instructions continued: "Please use the scale below to indicate how hard you found the rating task. Circle the most appropriate scale value." The scale ranged from 1 (very hard) to 5 (very easy). The participants were allowed $30 \mathrm{sec}$ to perform this rating. The next page contained a series of anagram completions and served as a 3-min distractor task. The participants were asked to complete as many anagrams as they could in the time provided.

The participants then turned to page 4 , which contained instructions for the recall portion of the study. The instructions read,

We would now like you to try to recall the words that you rated in the first part of the study. Please write the words, one per line, in the spaces provided below. You may recall the words in any order in which they come to mind.

The page contained 30 blank lines. Following a 3-min recall period, ${ }^{2}$ the participants turned to the final page of the booklet, where the instructions continued: "Please use the scale below to estimate approximately how many camping trips you have taken in your life. Circle the most appropriate answer." The scale values were " 0 ," "1-5," "6-10, "11-15" and "more than 15." The participants were given $30 \mathrm{sec}$ for this task, after which the booklets were collected and the participants debriefed.

\section{RESULTS}

A chi-square analysis revealed no statistically reliable differences among conditions in the number of camping trips that the participants estimated they had taken $\left[\chi^{2}(12)=11.42, p>.30\right]$. The modal number of trips taken was "1-5." Values of "0" (i.e., no camping experience) seldom occurred and were distributed approximately evenly across conditions: three in the survival condition, four in the planning condition, one in the atemporal condition, and three in the episodic condition. Because a response of " 0 " in the episodic condition renders performance of the encoding task impossible, the 3 participants with responses of " 0 " were replaced with 3 new participants (none of whom responded " 0 " on the experiencewith-camping question) prior to conducting the statistical analysis. Because the analyses yielded the same pattern of statistical significance whether or not the participants with responses of " 0 " were included in the data set, the analyses reported below are those performed on the complete data set.

Mean recall as a function of encoding task is presented in Figure 3. A one-way ANOVA conducted on recall scores yielded a reliable effect of task $[F(3,220)=5.28, p<.01] .^{3}$ Consistent with our predictions, planned comparisons ( $p<$ .05 ; Rosenthal \& Rosnow, 1985) revealed that the participants in the planning condition recalled significantly more words than did the participants in any of the other encoding conditions. Survival processing produced higher recall than did past processing, and this difference fell just short of significance $(p<.07)$ with respect to the atemporal condition. As can be seen in Figure 3, the results of the past and atemporal conditions were virtually identical.

To examine whether variables other than encoding task had an effect on recall, we also analyzed the participants' mean likeliness ratings. Although our pretest data enabled us to control task relevance within the list of 30 items, it is possible that the participants found the list words more relevant/likely (and hence more memorable; e.g., Brown,

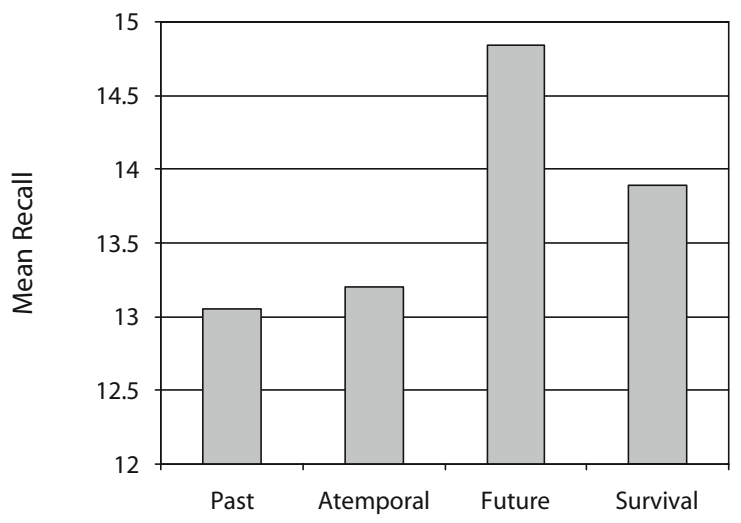

Figure 3. Mean recall of stimulus words (maximum possible = 30 words) as a function of encoding task. 


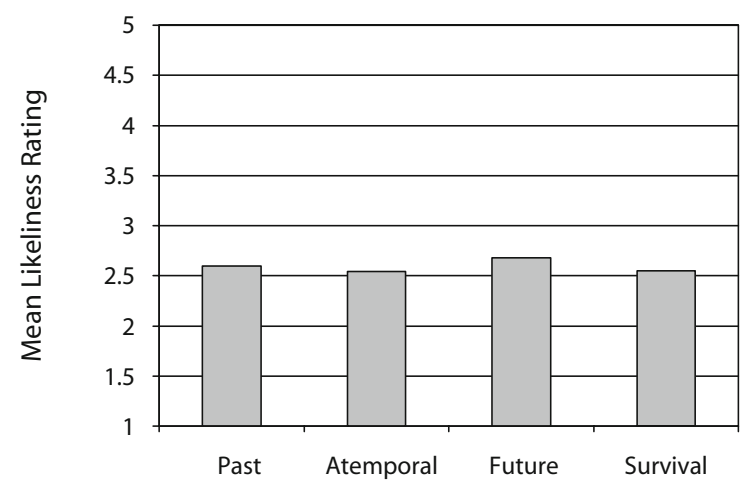

Figure 4. Mean likeliness ratings of stimulus words as a function of encoding task. Scale values ranged from 1 (very unlikely) to 5 (very likely).

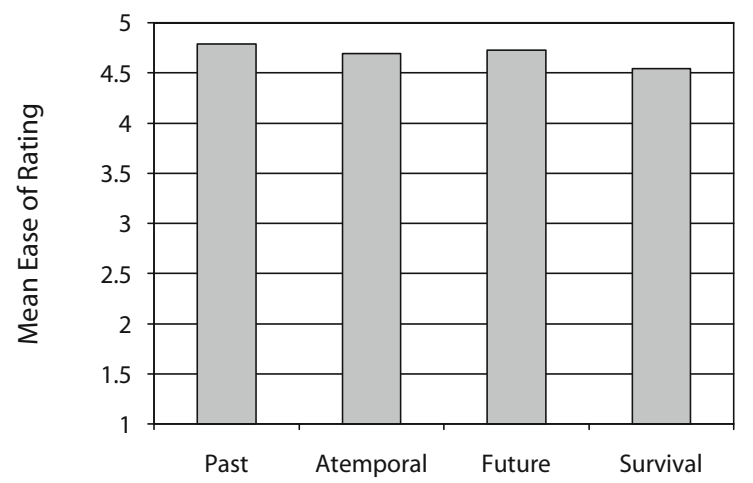

Figure 5. Mean ease of rating stimulus words as a function of encoding task. Scale values ranged from 1 (very hard) to 5 (very easy).

1976; Srull, 1981) in some encoding conditions than in others. However, a one-way ANOVA revealed no reliable differences in rated likeliness across conditions $[F(3,223)=$ 2.09 , n.s.]. As can be seen in Figure 4, the mean scores for all four encoding conditions were close to the scale mean (3.0), which is what one would expect given the word selection process described in the Method section.

Another question concerns whether the participants found some rating tasks easier to perform than others. Although differences in the ease of rating could potentially influence recall, it is hard to predict whether such an effect would necessarily be beneficial (e.g., Craik \& Tulving, 1975). Fortunately, a one-way ANOVA on mean ease of rating scores found no significant differences among the encoding conditions $[F(3,233)=2.96$, n.s. $]$. As is shown in Figure 5, the participants in all four conditions found their task very easy to perform, with mean ease of rating scores ranging between 4.54 and 4.79 on the 5-point scale.

\section{DISCUSSION}

Consistent with our predictions, future-oriented planning resulted in better memory than did past-oriented, atemporal, or survival processing. This result was anticipated on the basis of our arguments that memory systems include design features for interfacing with planning systems (e.g., Klein, Cosmides, et al., 2002), and that when planning is appropriately engaged, memory performance should be particularly efficient.

Replicating recent work by Nairne and his colleagues (e.g., Nairne \& Pandeirada, 2008a; Nairne et al., 2007), we also found that survival processing yielded recall performance superior to that found with more traditional encoding tasks. It exceeded performance on a past-oriented task (i.e., an episodic memory task) and fell just short of significance when compared with an atemporal processing task (i.e., a semantic memory task).

\section{Design for Planning}

Over the course of evolution, modifications in human memory have been incorporated to the extent that they have improved the functional operation of the system; that is, they increase the ability of neurocognitive machinery to successfully solve adaptive information-processing problems (e.g., Cosmides \& Tooby, 1987; Sherry \& Schacter, 1987). Planning and an orientation toward the future, two highly interrelated abilities, greatly enhance their owner's chances for survival. Accordingly, planning for future contingencies is, in our view, a specific, evolved set of mechanisms designed to help solve a general problem: how to remain alive long enough to reproduce and care for one's offspring.

Planning, itself, of course, is not a conceptual primitive; rather, it consists in a set of evolved component processes, each of which has its own evolved function (for traditional treatments, see Miller, Galanter, \& Pribram, 1960, and Schank \& Abelson, 1977; for a recent summary, see Lombardo, 2008). For example, to plan for one's future, one must, at a minimum, be able to (1) imagine possible futures, (2) set long-term personal goals, (3) construct hypothetical scenarios whose enactment will result in the realization of an intended goal, and (4) evaluate the likelihood that an imagined act will achieve the goal.

By contrast, it is not easy to enumerate a set of minimally necessary or sufficient behaviors for survival. Indeed, as it was developed in biological theory, the concept of survival encompasses everything that is not growth or reproduction - obviously an extremely heterogeneous set of activities and processes. So although natural selection can result in distinct adaptations for distinct facets of survival, it would be difficult for it to result in a single adaptation for survival (see also Nairne \& Pandeirada, 2008b).

A finding that remains to be addressed is that tasks associated with planning have been shown in previous research to be inferior to survival tasks with respect to recall performance (Kang, McDermott, \& Cohen, 2008; Nairne \& Pandeirada, 2008a, 2008b; Nairne et al., 2008; Nairne et al., 2007; Weinstein, Bugg, \& Roediger, 2008). There are at least two reasons for the discrepancies between our work and previous work. First, as was discussed in the introduction, the planning and survival tasks that were compared in previous studies differed along multiple dimensions, including, but not limited to, context (e.g., survival 
in the wild vs. planning an extended vacation vs. planning a move to a foreign country) and plausibility/familiarity of the planning scenario (planning a bank robbery, planning to protect oneself from attackers in a strange city). By contrast, in our study, the stimulus words all were processed in reference to the same familiar and plausible scenario: time spent in the woods.

In addition to methodological concerns, there are theoretical considerations that merit attention. Of particular relevance to planning tasks is a distinction proposed by Klein, Loftus, and Kihlstrom (2002) on the difference between lived time and known time. Lived time is personal, self-referential, and based on episodic memory (see also Tulving, 2002). When it is future-oriented, lived time recruits self-referential episodic recollections to serve as the basis for imagined personal scenarios (see also Boyer, 2007; Suddendorf \& Corballis, 1997; and Wheeler, Stuss, \& Tulving, 1997). In this regard, planning a camping trip (which more than $97 \%$ of our participants had personally experienced) clearly differed from the planning conditions used in previous studies. In those studies, the participants were unlikely to have had personally relevant experiences regarding the planning encouraged (e.g., a move to a foreign land, fighting attackers in the streets of a strange country, robbing a bank, taking a vacation at a fancy resort for several months). Rather, to the extent that temporality was involved in the construction of those scenarios (and there is no guarantee that it was; see our discussion visà-vis survival in the introduction), this was more likely to entail the type of experience termed known time - a form of mental time travel associated with semantic memory that allows a person to orient to imagined future events without experiencing them as a future part of his or her personal history. Known time enables its owner to know about, but not to reexperience, previous states of the world and to draw on this generic knowledge to construct impersonal scenarios for the future (e.g., Klein, Loftus, \& Kihlstrom, 2002).

Known time has many obvious benefits (e.g., the discovery of chronology, science, history), but it does not entail awareness of the temporal dimensions of one's own experience. The individual is only able to "chronologically locate facts in a temporal matrix that extends from the impersonal past to the impersonal future" (Klein, Loftus, \& Kihlstrom, 2002, p. 370). Accordingly, unlike either survival processing or the type of planning involved in the present study, it seems likely that previously adopted planning tasks lacked a personal real-world relevance that connected them in a meaningful way to the participants' actual experience. This connection with lived time, we believe, is crucial to the future-oriented function of memory (see below).

\section{Might Elaborative Processing Explain the High Recall Found With the Planning Task?}

A question consistently raised in reviews of this article was the extent to which the planning condition was more likely than the other experimental tasks to encourage elaborative processing. If this were the case, the superior recall found with the planning task might be accounted for by the greater elaborative encoding that it encourages, rather than its temporal orientation.

Several arguments make this suggestion less compelling with respect to the data at hand. First, as is depicted in Figure 5, the participants in all four experimental conditions found their encoding task decisions equally easy. Although this does not conclusively rule out differences in the amount of elaborative processing, it does lessen the possibility that the participants were differentially expending processing effort associated with trace elaboration (i.e., forming links between the stimulus words and extralist material in memory, which, unless it is assumed to be fully automatic, requires conscious effort). Although we did not measure response latency (another indirect measure of processing effort), other researchers have (e.g., Nairne et al., 2007), and that variable did not account for differences in recall among conditions.

Second, as was noted earlier, in a number of articles (e.g., Kang et al., 2008; Nairne et al., 2007) planning has been examined (albeit planning of a less self-relevant nature than the planning task used in the present study) and found to be both inferior to survival encoding and not reliably different from nonplanning encoding tasks with regard to recall. It would thus be difficult (though not impossible; see below) to maintain that our planning task enhanced elaboration, whereas a number of others did not.

This leads naturally to our third point: Since our planning task was likely more self-referential than the planning tasks used in previous studies, and since self-reference is well known to promote elaborative processing (e.g., Klein \& Loftus, 1988; for a review, see Symons \& Johnson, 1997), perhaps it is the self-relevance of our planning task that accounts for the elaborative benefits that have been proposed to mediate our recall findings. However, our planning task was not alone in its self-referential demands: Most of our tasks were clearly self-referential (i.e., the past, survival, and planning tasks), yet differences in recall still were evident. Moreover, Nairne et al. (2007) specifically compared a self-reference encoding task with their survival task and found that the self-reference task yielded inferior recall. It is thus hard to see how the superior recall that we found with planning could be the result of elaborative processing, whereas a task explicitly known to produce high levels of elaboration - the self-reference task - yielded recall inferior to survival processing (a task that, in the present study, was slightly inferior to planning processing in the amount of recall that it produced).

Finally, and most important, the data from the present experiment fail to support an elaborative processing explanation. As was noted in the introduction, when undertaking the planning process, there are a potentially limitless number of contingencies that one might consider, only a subset of which need be acted on. Because of this, a memory system designed to interact with planning systems should be capable of tracking whether a given course of action (e.g., bringing a first-aid kit to the woods) has been considered during the current planning routine. This should occur even when the potential course of action is ultimately de- 
termined to be irrelevant (e.g., bringing a desk); indeed, it would be particularly wasteful to reconsider a course of action already deemed useless. Therefore, compared with our comparison tasks (particularly the past-oriented and atemporal tasks), planning should elicit particularly good recall for items deemed irrelevant to the camping situation. With regard to the relevant items, by contrast, recall predictions are harder to make. This is because the relevant items form a well-defined set clearly organized around the task requested in each condition (i.e., items relevant to camping and/or survival) and because task relevance and organization (both variables known to benefit recall) are similar across conditions (see note 1 ).

Accordingly, we propose the counterintuitive prediction-yet, one easily inferred from the evolutionary considerations that we discussed in the introduction - that although relevant items will be better recalled than irrelevant items, the overall recall advantage found for the planning task will be due largely to memory for irrelevant items.

To test this, we conducted a one-way ANOVA on the number of irrelevant items recalled by the participants in each experimental condition. The results produced a significant main effect $[F(3,223)=11.39, p<.05]$ with planning yielding the highest recall of irrelevant items $(M=6.13)$, followed by survival $(M=5.32)$, atemporal encoding $(M=4.55)$, and past-oriented encoding $(M=$ 4.36). Tukey tests $(p<.05)$ showed that, as was predicted, planning encoding produced significantly better recall of irrelevant items than did either atemporal or past-oriented encoding. The recall of irrelevant items in the survival condition exceeded that in the past-oriented condition and fell just short of significance when compared with the atemporal condition $(p<.07)$. Finally, the planning condition showed marginally greater recall of irrelevant items than did the survival condition $(p<.06)$.

As an additional check on our predictions, we subtracted the mean number of irrelevant items recalled in each condition from the total number of items remembered in the corresponding condition. This resulted in a score representing the mean number of relevant items recalled per condition. The findings (planning, $M=8.71$; survival, $M=8.57$; atemporal, $M=8.65$; and past, $M=$ 8.69) show that relevant items were recalled equally well across conditions. Clearly, the superior recall evidenced by planning (and, to a slightly lesser degree, by survival processing) appears to be due to differences in the recall of irrelevant items.

Taken together, these results are predicted by our evolutionary analysis. By contrast, they are hard to explain in terms of the argument that planning induces deeper or more elaborative processing. If it did, why would the overall recall advantage not also be reflected in the recall of relevant items? A ceiling effect interpretation seems doubtful, given that there were 15 relevant items, of which only about half were remembered in each condition.

In summary, differences in trace elaboration, processing effort, relevance to the task, and self-referential processing are not easily supported by our data. In ad- dition, Nairne et al. (2007) carefully examined many of these variables using additional measures (e.g., response latency) and showed them to be less than accommodating as alternate explanations.

\section{Human Memory Research: \\ A Reorientation of Temporal Focus}

Despite the theoretical reasons for which long-term information storage and retrieval should be expected to be oriented to the future, research on human memory has traditionally focused on memory's apparent orientation to the past (the prospective memory movement is an obvious exception to the rule; for a review, see Brandimonte, Einstein, \& McDaniel, 1996). For example, in Hoerl and McCormack's (2001) edited volume Time and Memory, only about 13 of the more than 400 pages examining the relation between memory and time are devoted to planning and thinking about the future. By contrast, half of the themed subsections of the volume are specifically concerned with memory and the past (e.g., "Memory, Awareness, and the Past" and "Knowledge and the Past").

Fortunately, this is now starting to change. For example, considerable research has been devoted to exploring the memorial underpinnings of what is referred to as mental time travel (a concept initially explored by Tulving, 1985, and explicitly mapped by Suddendorf, 1994). Although Tulving's (1985) and Suddendorf's concerns were with both retrospective and prospective functions of mental time travel, initial treatment focused largely on people's ability to use long-term memory to travel into their past (for reviews of research and emerging trends, see Suddendorf \& Corballis, 2007, along with the associated peer commentaries; Tulving, 2002). More recently, the prospective function of mental time travel has come to occupy an increasingly prominent place in research and theory (e.g., Atance \& O'Neill, 2005; Botzung, Denkova, \& Manning, 2008; Buckner \& Carroll, 2007; Busby \& Suddendorf, 2005; Schacter, Addis, \& Buckner, 2007; Weiler \& Daum, 2008).

Work on episodic long-term memory (the neural system hypothesized by Tulving [1985] and Suddendorf [1994] to enable mental time travel) reveals a similar shift in temporal focus. As it was initially conceptualized, episodic memory was held to consist in knowledge of a previously experienced event along with an awareness that the event occurred in one's past (e.g., Tulving, 1972, 1983). Episodic recollection thus enabled a person to mentally travel back in time to relive previously experienced personal events. However, episodic memory has more recently been hypothesized to provide a foundation for imagining what one's experiences might be like in the future, thereby enabling its owner to plan future actions and to anticipate future events (e.g., Boyer, 2007; Dalla Barba, 2001; Hassabis, Kumaran, Vann, \& Maguire, 2007; Klein, Loftus, \& Kihlstrom, 2002; Schacter, Addis, \& Buckner, 2008; Suddendorf \& Corballis, 2007; Szpunar \& McDermott, 2008; Szpunar, Watson, \& McDermott, 2007; Tulving \& Lepage, 2000; Wheeler et al., 1997). In this regard, we have identified another potential function of episodic memory 
(e.g., Klein et al., 2009; Klein, Cosmides, et al., 2002): the ability to project oneself not only into the past, but to imagine (and thus plan for) one's existence in the future.

In summary, researchers are increasingly appreciating that careful theoretical and empirical consideration of all three temporal possibilities — past, present, and future - is essential if one hopes to understand the evolved functions of the human memory system. Indeed, it is possible that memory enabled humans to be aware of the future before they were able to consciously experience the past. However, regardless of whether that proposal turns out to be correct, an understanding of the inherently future-oriented nature of information processing appears increasingly essential for the study of human memory.

\section{AUTHOR NOTE}

We thank the UCSB Social Brownbag for their helpful comments on a previous draft of this article. Correspondence concerning this article should be addressed to S. B. Klein, Department of Psychology, 551 Ucen Road, University of California, Santa Barbara, CA 93106 (e-mail: klein@psych.ucsb.edu).

\section{REFERENCES}

Atance, C. M., \& O'Neill, D. K. (2005). The emergence of episodic future thinking in humans. Learning \& Motivation, 36, 126-144.

Barkow, J. H., Cosmides, L., \& ToOBY, J. (EDs.) (1992). The adapted mind: Evolutionary psychology and the generation of culture. New York: Oxford University Press.

BISCHOF-KÖHLER, D. (1985). Zur Phylogenese menschlicher Motivation [On the phylogeny of human motivation]. In L. H. Eckensberger \& E. D. Lantermann (Eds.), Emotion und Reflexivität (pp. 3-47). Vienna: Urban \& Schwarzenberg.

Botzung, A., Denkova, E., \& Manning, L. (2008). Experiencing past and future personal events: Functional neuroimaging evidence on the neural bases of mental time travel. Brain \& Cognition, 66, 202-212.

BOYER, P. (2001). Religion explained: The evolutionary origins of religious thought. New York: Basic Books.

BOYER, P. (2007). Why do we have episodic memories? Mental time-travel as a strategic incentive mechanism. Unpublished manuscript.

Brandimonte, M., Einstein, G. O., \& McDaniel, M. A. (Eds.) (1996). Prospective memory: Theory and applications. Mahwah, NJ: Erlbaum. BRown, J. (ED.) (1976). Recall and recognition. New York: Wiley.

Buckner, R. L., \& Carroll, D. C. (2007). Self-projection and the brain. Trends in Cognitive Sciences, 11, 49-57.

BusBY, J., \& SudDENDORF, T. (2005). Recalling yesterday and predicting tomorrow. Cognitive Development, 20, 362-372.

Cosmides, L., \& TоовY, J. (1987). From evolution to behavior: Evolutionary psychology as the missing link. In J. Dupré (Ed.), The latest on the best: Essays on evolution and optimality (pp. 277-306). Cambridge, MA: MIT Press.

Craik, F. I. M., \& Tulving, E. (1975). Depth of processing and the retention of words in episodic memory. Journal of Experimental Psychology: General, 104, 268-294.

Dalla Barba, G. (2001). Memory, consciousness, and temporality. London: Kluwer.

DawkIns, R. (1976). The selfish gene. Oxford: Oxford University Press.

Donald, M. (1991). Origins of the modern mind: Three stages in the evolution of culture and cognition. Cambridge, MA: Harvard University Press.

Donald, M. (2001). A mind so rare: The evolution of human consciousness. New York: Norton \& Company.

DUNBAR, R. (1996). Grooming, gossip, and the evolution of language. Cambridge, MA: Harvard University Press.

Gibson, K. R., \& IngOLD, T. (EDS.) (1993). Tools, language, and cognition in human evolution. New York: Cambridge University Press.

Hassabis, D., Kumaran, D., Vann, S. D., \& Maguire, E. A. (2007). Patients with hippocampal amnesia cannot imagine new experiences. Proceedings of the National Academy of Sciences, 104, 1726-1731.
HoERL, C., \& MCCoRMack, T. (EDS.) (2001). Time and memory: Issues in philosophy and psychology. Oxford: Clarendon Press.

JoHnson, D. M. (2003). How history made the mind: The cultural origins of objective thinking. Chicago: Open Court.

Kang, S. H. K., McDermott, K. B., \& Cohen, S. M. (2008). The mnemonic advantage of processing fitness-relevant information. Memory \& Cognition, 36, 1151-1156.

Kenrick, D. T., Delton, A. W., Robertson, T. E., Becker, D. V., \& NeUberG, S. L. (2007). How the mind warps: Processing disjunctions may elucidate ultimate functions. In J. P. Forgas, M. G. Haselton, \& W. von Hippel (Eds.), Evolution and the social mind: Evolutionary psychology and social cognition (pp. 49-68). New York: Psychology Press.

KLEIN, S. B. (2007). Phylogeny and evolution: Implications for understanding the nature of a memory system. In H. L. Roediger III, Y. Dudai, \& S. M. Fitzpatrick (Eds.), Science of memory: Concepts (pp. 377-381). Oxford: Oxford University Press.

Klein, S. B., Cosmides, L., Gangi, C. E., Jackson, B., Tooby, J., \& Costabile, K. A. (2009). Evolution and episodic memory: An analysis and demonstration of a social function of episodic memory. Social Cognition, 27, 283-319.

Klein, S. B., Cosmides, L., Tooby, J., \& Chance, S. (2002). Decisions and the evolution of memory: Multiple systems, multiple functions. Psychological Review, 109, 306-329.

KLEIN, S. B., \& Kinlstrom, J. F. (1986). Elaboration, organization, and the self-reference effect in memory. Journal of Experimental Psychology: General, 115, 26-38.

KLEIN, S. B., \& LofTUS, J. (1988). The nature of self-referent encoding: The contributions of elaborative and organizational processes. Journal of Personality \& Social Psychology, 55, 5-11.

KLEIN, S. B., \& LofTus, J. (1990). Rethinking the role of organization in person memory: An independent trace storage model. Journal of Personality \& Social Psychology, 59, 400-410.

Klein, S. B., Loftus, J., \& Kinlstrom, J. F. (2002). Memory and temporal experience: The effects of episodic memory loss on an amnesic patient's ability to remember the past and imagine the future. Social Cognition, 20, 353-379.

LOMBARDO, T. (2008). The evolution of future consciousness. Bloomington, IN: AuthorHouse.

Maner, J. K., Kenrick, D. T., Becker, D. V., Delton, A. W., Hofer, B., Wilbur, C. J., \& Neuberg, S. L. (2003). Sexually selective cognition: Beauty captures the mind of the beholder. Journal of Personality \& Social Psychology, 85, 1107-1120.

Miller, G. A., Galanter, E., \& Pribram, K. H. (1960). Plans and the structure of behavior. New York: Holt, Rinehart, \& Winston.

Mithen, S. J. (1996). The prehistory of the mind: The cognitive origins of art, religion and science. London: Thames \& Hudson.

MumFord, L. (1934). Technics and civilization. New York: Harcourt.

Nairne, J. S., \& Pandeirada, J. N. S. (2008a). Adaptive memory: Is survival processing special? Journal of Memory \& Language, 59, 377-385.

Nairne, J. S., \& Pandeirada, J. N. S. (2008b). Adaptive memory: Remembering with a stone-age brain. Current Directions on Psychological Science, 17, 239-243.

Nairne, J. S., Pandeirada, J. N. S., \& Thompson, S. R. (2008). Adaptive memory: The comparative value of survival processing. Psychological Science, 19, 176-180.

Nairne, J. S., Thompson, S. R., \& Pandeirada, J. N. S. (2007). Adaptive memory: Survival processing enhances retention. Journal of Experimental Psychology: Learning, Memory, \& Cognition, 33, 263-273.

Passingham, R. E. (1982). The human primate. San Francisco: Freeman. Rosenthal, R., \& Rosnow, R. L. (1985). Contrast analysis: Focused comparisons in the analysis of variance. New York: Cambridge University Press.

SCHACTER, D. L., AdDIs, D. R., \& BucKNeR, R. L. (2007). Remembering the past to imagine the future: The prospective brain. Nature Reviews Neuroscience, 8, 657-661.

Schacter, D. L., Addis, D. R., \& Buckner, R. L. (2008). Episodic simulation of future events: Concepts, data, and applications. Annals of the New York Academy of Sciences, 1124, 39-60.

Schacter, D. L., \& Tulving, E. (Eds.) (1994). Memory systems 1994. Cambridge, MA: MIT Press.

SCHANK, R. C., \& AbELSON, R. P. (1977). Scripts, plans, goals and un- 
derstanding: An inquiry into human knowledge structures. Hillsdale, NJ: Erlbaum.

Sherry, D. F., \& Schacter, D. L. (1987). The evolution of multiple memory systems. Psychological Review, 94, 439-454.

SRULL, T. K. (1981). Person memory: Some tests of associative storage and retrieval models. Journal of Experimental Psychology: Human Learning \& Memory, 7, 440-463.

SUdDENDORF, T. (1994). Discovery of the fourth dimension: Mental time travel and human evolution. Unpublished master's thesis, University of Waikato, Hamilton, New Zealand.

Suddendorf, T., \& Corballis, M. C. (1997). Mental time travel and the evolution of the human mind. Genetic, Social, \& General Psychology Monographs, 123, 133-167.

SudDEndorf, T., \& Corballis, M. C. (2007). The evolution of foresight: What is mental time travel, and is it unique to humans? Behavioral \& Brain Sciences, 30, 299-313.

Symons, C. S., \& Johnson, B. T. (1997). The self-reference effect in memory: A meta-analysis. Psychological Bulletin, 121, 371-394.

SzPunar, K. K., \& McDermott, K. B. (2008). Episodic future thought and its relation to remembering: Evidence from ratings of subjective experience. Consciousness \& Cognition, 17, 330-334.

Szpunar, K. K., Watson, J. M., \& McDermott, K. B. (2007). Neural substrates of envisioning the future. Proceedings of the National Academy of Sciences, 104, 642-647.

Tulving, E. (1972). Episodic and semantic memory. In E. Tulving \& W. Donaldson (Eds.), Organization of memory (pp. 381-403). New York: Academic Press.

Tulving, E. (1983). Elements of episodic memory. New York: Oxford University Press.

Tulving, E. (1985). Memory and consciousness. Canadian Psychology, 26, 1-12.

Tulving, E. (2002). Chronesthesia: Conscious awareness of subjective time. In D. T. Stuss \& R. T. Knight (Eds.), Principles of frontal lobe function (pp. 311-325). New York: Oxford University Press.

Tulving, E., \& Craik, F. I. M. (EDs.) (2000). The Oxford handbook of memory. New York: Oxford University Press.

Tulving, E., \& Lepage, M. (2000). Where in the brain is the awareness of one's past? In D. L. Schacter \& E. Scarry (Eds.), Memory, brain, and belief (pp. 208-228). Cambridge, MA: Harvard University Press.

WeILer, J. A., \& Daum, I. (2008). Mental time travel: The neurocognitive basis of future thinking. Fortschritte der Neurologie $\bullet$ Psychiatrie, 76, 539-548.

Weinstein, Y., BugG, J. M., Roediger, H. L., III (2008). Can the survival recall advantage be explained by basic memory processes? Memory \& Cognition, 36, 913-919.

Wheeler, M. A., Stuss, D. T., \& Tulving, E. (1997). Toward a theory of episodic memory: The frontal lobes and autonoetic consciousness. Psychological Bulletin, 121, 331-354.

Williams, G. C. (1966). Adaptation and natural selection: A critique of some current evolutionary thought. Princeton, NJ: Princeton University Press.

\section{NOTES}

1. All four encoding conditions (the fourth encoding condition will be discussed shortly) share this conceptual organization and are thus equated along this dimension. Our prediction of superior recall found with survival and planning encoding is based on the addition of futureoriented processing encouraged by these two tasks.

2. Although researchers examining survival encoding typically utilize a 10-min recall interval, an analysis of cumulative recall by Nairne and Pandeirada (2008) revealed that a reliable advantage for survival tasks over comparison recall tasks emerges after 3 min and remains statistically stable for the duration of the 10-min interval (see Figure 1 in Nairne \& Pandeirada, 2008). Accordingly, we limited our recall interval to $3 \mathrm{~min}$, and, as will be seen, a survival advantage did occur with regard to our standard comparison tasks (but not, as was predicted, with regard to our planning task).

3. In an additional set of analyses, we also entered gender as a factor. No reliable effect of gender on amount recalled was found.

\begin{tabular}{|c|c|}
\hline \multicolumn{2}{|c|}{$\begin{array}{l}\text { APPENDIX } \\
\text { Words Unlikely and Likely to Be Associated } \\
\text { With Spending Time in the Woods }\end{array}$} \\
\hline Unlikely & Likely \\
\hline $\begin{array}{l}\text { bookcase } \\
\text { lawn mower } \\
\text { drapes } \\
\text { television } \\
\text { microwave } \\
\text { couch } \\
\text { dresser } \\
\text { rug } \\
\text { stapler } \\
\text { vacuum } \\
\text { puppet } \\
\text { treadmill } \\
\text { painting } \\
\text { modem } \\
\text { desk }\end{array}$ & $\begin{array}{l}\text { knife } \\
\text { batteries } \\
\text { binoculars } \\
\text { first-aid kit } \\
\text { bowls } \\
\text { matches } \\
\text { garbage bags } \\
\text { rope } \\
\text { water } \\
\text { tent } \\
\text { bread } \\
\text { grill } \\
\text { bug repellent } \\
\text { can opener } \\
\text { flashlight }\end{array}$ \\
\hline
\end{tabular}

(Manuscript received May 6, 2009; revision accepted for publication June 25, 2009.) 